\title{
Recurrence and Its Impact on the Health-related Quality of Life in Patients with Gastroesophageal Reflux Disease: A Prospective Follow-up Analysis
}

\author{
Yang Won Min, ${ }^{1}$ Yong Woon Shin, ${ }^{2}$ Gab Jin Cheon, ${ }^{3}$ Kyung Sik Park, ${ }^{4}$ Hyun Soo Kim, ${ }^{5}$ Chong-Il Sohn, ${ }^{6}$ Tae Nyeun Kim, \\ Hyeung Cheol Moon, and Poong-Lyul Rhee ${ }^{1 *}$ \\ ${ }^{I}$ Department of Medicine, Samsung Medical Center, Sungkyunkwan University School of Medicine, Seoul, Korea; ${ }^{2}$ Department of Internal \\ Medicine, Inha University College of Medicine, Incheon, Korea; ${ }^{3}$ Department of Internal Medicine, Gangneung Asan Hospital, Ulsan University \\ College of Medicine, Gangneung; Korea; ${ }^{4}$ Department of Internal Medicine, Keimyung University School of Medicine, Daegu, Korea; ${ }^{5}$ Department \\ of Internal Medicine, Daegu Fatima Hospital, Daegu, Korea; ${ }^{6}$ Department of Medicine, Kangbuk Samsung Hospital, Sungkyunkwan University \\ School of Medicine, Seoul, Korea; ${ }^{7}$ Department of Internal Medicine, Yeungnam University Hospital, Daegu, Korea; and ${ }^{8}$ Department of Internal \\ Medicine, Kwangju Christian Hospital, Gwangju, Korea
}

\section{Background/Aims}

Limited data exist on the outcome of gastroesophageal reflux disease (GERD) treatment and its impact on the health-related quality of life (HRQoL) in the Asian population. This study aims to evaluate the treatment outcomes, to investigate the factors associated with recurrence, and to evaluate the impact of the treatment outcome on the HRQoL in a Korean GERD population.

\section{Methods}

This was a prospective, multicenter study involving a total of 824 GERD patients. The response to treatment was assessed at week 4 (or week 8 for the patients who did not achieve complete resolution [CR] at week 4). The EQ-5D questionnaire was used at baseline, end of treatment, and first recurrence to assess the HRQoL. To assess GERD symptoms, contact of patients by phone at 1, 6, and 12 months following treatment was carried out.

\section{Results}

CR was achieved in $65.6 \%$ and recurrence was observed in $47.8 \%$ following treatment. CR and recurrence rates did not differ by the presence of esophagitis. Multivariate analysis revealed that acid regurgitation (odds ratio 2.249; $95 \%$ confidence interval 1.293-3.912; $P=0.004$ ) and both acid regurgitation and heartburn (odds ratio $2.330 ; 95 \%$ confidence interval $1.392-3.901 ; P=0.001$ ) were independent risk factors for GERD recurrence. EQ-5D scores were more improved in patients with $C R$ than in those without $C R$, and worsened more during follow-up in patients with recurrence than in those without recurrence.

\section{Conclusions}

We should achieve complete symptom relief and attempt to prevent recurrence in GERD patients to improve their HRQoL.

(J Neurogastroenterol Motil 2016;22:86-93)

Key Words

Gastroesophageal reflux; Quality of life; Recurrence; Therapy

Received: July 30, 2015 Revised: September 3, 2015 Accepted: September 7, 2015

(a) This is an Open Access article distributed under the terms of the Creative Commons Attribution Non-Commercial License (http://creativecommons. org/licenses/by-nc/4.0) which permits unrestricted non-commercial use, distribution, and reproduction in any medium, provided the original work is properly cited.

*Correspondence: Poong-Lyul Rhee, MD, PhD Department of Medicine, Samsung Medical Center, Sungkyunkwan University School of Medicine, 81 Irwon-ro, Gangnam-gu, Seoul 06351, Korea

Tel: +82-2-3410-3409, Fax: +82-2-3410-6983, E-mail: plrhee@skku.edu 


\section{Introduction}

Although proton pump inhibitor (PPI) therapy is effective for patients with gastroesophageal reflux disease (GERD), many patients will relapse over time when they are no longer taking PPIs. ${ }^{1-3}$ Thus, maintenance PPI therapy is recommended for patients who continue to have symptoms after discontinuing PPIs, and for patients with complications including erosive esophagitis and Barrett's esophagus. In Eastern Asia, the lifestyle and dietary habits have changed towards a more Western style, and the prevalence of GERD is likely to have increased as a result. ${ }^{4-9}$ However, limited data exist on the response to PPI therapy and the recurrence of GERD in East Asian countries, including Korea. ${ }^{10-13}$

Patients with GERD have a decreased health-related quality of life (HRQoL). ${ }^{12,14,15}$ Although HRQoL improves with treatment, persistent symptoms after PPI therapy are associated with a reduced HRQoL. ${ }^{14,16,17}$ However it is unclear how the recurrence of GERD symptoms impacts patients' HRQoL. Furthermore, there have been no reports regarding the difference in the impact of relapsed GERD symptoms on HRQoL between patients with erosive reflux disease (ERD) and non-erosive reflux disease (NERD).

The aim of the current study is to evaluate the response rate to PPI therapy and the post-treatment recurrence rate in a Korean GERD population. In addition, we investigated the factors associated with recurrence and assess HRQoL in patients with GERD.

\section{Materials and Methods}

\section{Study Design and Population}

This was a prospective, multicenter, observational study involving a total of 857 GERD patients among 23 hospitals in South Korea. Patients aged between 20 and 80 years, who complained of typical reflux symptoms of heartburn and/or regurgitation were consecutively enrolled into this study. The study subjects underwent an upper endoscopy within the preceding 12 months and were supposed to take no acid suppressing agents at least 4 weeks before enrollment. The first subject was enrolled on the 7th of July 2011 and the last visit of all subjects was on the 21st of September 2013. Subjects who fell under any of the following criteria were excluded: (1) any previous gastrointestinal surgery; (2) any malignancies; (3) significant medical comorbidity including ischemic heart disease, chronic renal disease, congestive heart failure, chronic obstructive pulmonary disease, liver cirrhosis, and acute or chronic pancreatitis;
(4) pregnant or nursing women; (5) subjects who participated in another clinical study within 30 days or are currently enrolled in; and (6) other conditions likely to interfere with study procedures, as judged by the investigator. Of the participating subjects, 33 were excluded from the study: 13 used acid suppressing agents during the 4 week period preceding enrollment, 10 had histories of malignancy, 7 had significant ischemic heart disease or chronic renal disease, and 5 had no typical reflux symptoms. Finally, a total of 824 consecutive patients were included in the current study (Fig. 1). This study protocol was conducted in accordance with the Declaration of Helsinki and approved by the Institutional Review Board at the Samsung Medical Center, Seoul, Korea (No. 2011-08-109). All subjects provided written informed consent before inclusion in the study.

\section{Data Collection and Questionnaire}

At baseline, data including age, gender, weight, height, waist circumference, hip circumference, smoking history, drinking history, concomitant medications, previous medical history, and previous GERD treatment history were collected. The response to treatment was assessed by interview with an attending physician at week 4 (or week 8 for the patients who did not achieve complete resolution [CR] at week 4).

The EuroQol-5D-3L ${ }^{18}$ (EQ-5D-3L) questionnaire was used at baseline, end of treatment (week 4 or week 8), and first recurrence (if applicable) to assess the impact of GERD on HRQoL. The EQ-5D-3L questionnaire consisted of a descriptive system and visual analogue scale (VAS). The EQ descriptive system comprises the following 5 dimensions: mobility, self-care, usual activities, pain/discomfort, and anxiety/depression. Each dimension has 3 levels: no problems, some problems, and extreme problems.

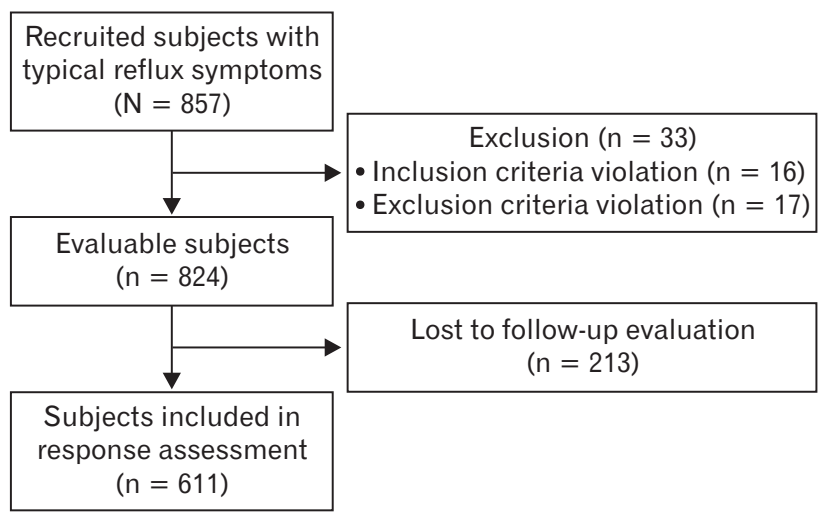

Figure 1. Patients flow. 
The EQ VAS records the respondent's self-rated health on a vertical, visual analogue scale (from 0 to 100), where the endpoints are labelled "best imaginable health state" and "worst imaginable health state." Higher scores represent a better health status.

To assess GERD symptoms, phone contact at 1, 6, and 12 months following the end of treatment was conducted on the subjects without recurring disease. This survey was conducted by the contract research company Gallup using structured questions. If a subject visited after a recurrence, a phone contact was only carried out at month 12 .

\section{Definitions and Assessments}

Subjects were divided into ERD or NERD based on the endoscopic findings, according to the Los Angeles (LA) classification system. ${ }^{19}$ Subjects with at least grade LA-A esophagitis were included in the ERD group. Response to treatment was categorized into 4 grades (CR, $\geq 80 \%$ of the symptoms resolved; satisfactory resolution, $\leq 50 \%$ of the symptoms remained; partial response, $\geq 50 \%$ of the symptoms remained; and refractory response, no response to the 8-week PPI treatment). Recurrence was defined as the recurrence of typical symptoms of reflux after complete resolution of GERD symptoms.

The primary outcomes were the response rate to PPI treatment and the post-treatment recurrence rate. The secondary outcomes were the factors associated with the recurrence of GERD following PPI treatment and the difference between ERD and NERD in terms of the rate of $\mathrm{CR}$ with the treatment, the rate of recurrence, and HRQOL.

\section{Statistical Methods}

The current study is an observatory, descriptive study based on routine medical practice without any intervention except the measurement of HRQoL using verified questionnaires. Therefore, the estimation of the required number of subjects based on the estimation of statistical power could not be applied to this study. Considering the number of patients who visited 30 representative study sites during a 6 month period, our intended study period, we planned to recruit 2000 subjects. The full analysis set $(n=824)$ defined as the subject group without serious violation at enrollment was used for analysis, and the response to PPI treatment and recurrence could be confirmed in 611 subjects.

Continuous variables were compared parametrically using a Student's $t$ test or non-parametrically using the Mann-Whitney U-test. Categorical variables were compared using the $\chi^{2}$-test or Fisher's exact test as appropriate. Multivariate analysis was per- formed on variables that were associated with recurrence based on univariate analysis $(P<0.2)$. Odds ratios $(\mathrm{ORs})$ were presented together with $95 \%$ confidence intervals $(\mathrm{CI})$. Statistical results are presented as the mean $\pm \mathrm{SD}$, median (minimum and maximum), or number of patients (\%). Two-sided $P$-values $<0.05$ were taken as statistically significant. Statistical analyses were conducted using SAS version 9.2 (SAS Institute Inc, Cary, North Carolina, USA).

\section{Results}

\section{Subject Characteristics}

Baseline characteristics of subjects are summarized in Table 1. The mean age was $53.7 \pm 12.3$ years and 361 patients $(43.8 \%)$ were male. The mean height, weight, and body mass index (BMI) were $162.5 \pm 8.3 \mathrm{~cm}, 62.1 \pm 11.1 \mathrm{~kg}$, and $23.4 \pm 3.1 \mathrm{~kg} / \mathrm{m}^{2}$, respectively. The mean waist circumference, hip circumference, and waist/hip $(\mathrm{W} / \mathrm{H})$ ratio were $84.4 \pm 10.4 \mathrm{~cm}, 96.6 \pm 9.0 \mathrm{~cm}$, and 0.9 \pm 0.1 , respectively. A total of 150 subjects (18.2\%) had hypertension. Regarding smoking, 589 subjects $(71.5 \%)$ were non-smokers, 135 (16.4\%) current smokers (mean $20.8 \pm 12.3$ pack-years), and $100(12.1 \%)$ ex-smokers (mean $22.4 \pm 13.8$ pack-years). The number of times alcohol was drunk per week was $0.8 \pm 1.6$ times. Normal or minimal change lesion on endoscopy in the lower esophagus (NERD) was shown in 341 subjects (41.4\%), while 483 (58.6\%) had reflux esophagitis (ERD). Of the 824 subjects who participated in the current study, 281 (34.1\%) complained of heartburn, 203 (24.6\%) experienced regurgitation, and 340 (41.3\%) had both. Atypical esophageal symptoms were also observed in 711 subjects $(86.2 \%)$. The most prevalent symptom was epigastric burning in 542 subjects (76.2\%), followed by globus sensation in 389 (54.7\%), chest pain in 303 (42.6\%), a cough in 250 (35.2\%), hoarseness in 155 (21.8\%), and wheezing in 78 (11.0\%). The most common PPI used was esomeprazole (82.9\%). The characteristics of all study participants are similar to that of subjects included in the response assessment.

\section{Treatment Response and Recurrence Rate}

Figure 2 shows the similar treatment responses between patients with $\mathrm{ERD}$ and $\operatorname{NERD}(P=0.835)$. Among the 611 subjects assessed at the end of the treatment, a CR was present in 401 $(65.6 \%)$, a satisfactory resolution in $132(21.6 \%)$, a partial response in $70(11.5 \%)$, and a refractory response in $8(1.3 \%)$. The CR rate did not differ between patients with ERD and NERD (64.5\% vs $67.2 \%, P=0.494)$. Among the subjects with $\mathrm{CR}$, recurrence was 
Table 1. Baseline Characteristics of Subjects

\begin{tabular}{|c|c|c|}
\hline Variables & $\begin{array}{l}\text { All subjects } \\
(\mathrm{n}=824)\end{array}$ & $\begin{array}{l}\text { Subjects included in response assessment } \\
\qquad(\mathrm{n}=611)\end{array}$ \\
\hline Age (yr) & $53.7 \pm 12.3$ & $54.2 \pm 12.2$ \\
\hline Gender (male) & $361(43.8)$ & $266(43.5)$ \\
\hline Height (cm) & $162.5 \pm 8.3$ & $162.3 \pm 8.3$ \\
\hline Weight (kg) & $62.1 \pm 11.1$ & $62.2 \pm 11.2$ \\
\hline Body mass index $\left(\mathrm{kg} / \mathrm{m}^{2}\right)$ & $23.4 \pm 3.1$ & $23.5 \pm 3.2$ \\
\hline Waist circumference $(\mathrm{cm})$ & $84.4 \pm 10.4$ & $84.6 \pm 10.5$ \\
\hline Hip circumference (cm) & $96.6 \pm 9.0$ & $96.8 \pm 9.2$ \\
\hline Waist/hip ratio & $0.9 \pm 0.1$ & $0.9 \pm 0.1$ \\
\hline Hypertension & $150(18.2)$ & $133(18.5)$ \\
\hline \multicolumn{3}{|l|}{ Smoking } \\
\hline Non-smoker & $589(71.5)$ & $449(73.5)$ \\
\hline Ex-smoker & $100(12.1)$ & $68(11.1)$ \\
\hline Current smoker & $135(16.4)$ & $94(15.4)$ \\
\hline Days of drinking per week & $0.8 \pm 1.6$ & $0.8 \pm 1.6$ \\
\hline ERD:NERD & $483(58.6): 341(41.4)$ & $358(58.6): 253(41.4)$ \\
\hline \multicolumn{3}{|l|}{ Typical reflux symptom } \\
\hline Acid regurgitation & $203(24.6)$ & $153(25.0)$ \\
\hline Heartburn & $281(34.1)$ & $212(34.7)$ \\
\hline Both symptoms & $340(41.3)$ & $246(40.3)$ \\
\hline Atypical esophageal symptom & $711(86.2)$ & $530(86.7)$ \\
\hline \multicolumn{3}{|l|}{ Type of $\mathrm{PPI}^{\mathrm{a}}$} \\
\hline Esomeprazole & $682(82.9)$ & $518(84.8)$ \\
\hline Others & $164(20.0)$ & $116(18.9)$ \\
\hline
\end{tabular}

aThere were multiple counts.

ERD, erosive reflux disease; NERD, non-erosive reflux disease.

Data are shown as the mean \pm SD or number $(\%)$ of patients.

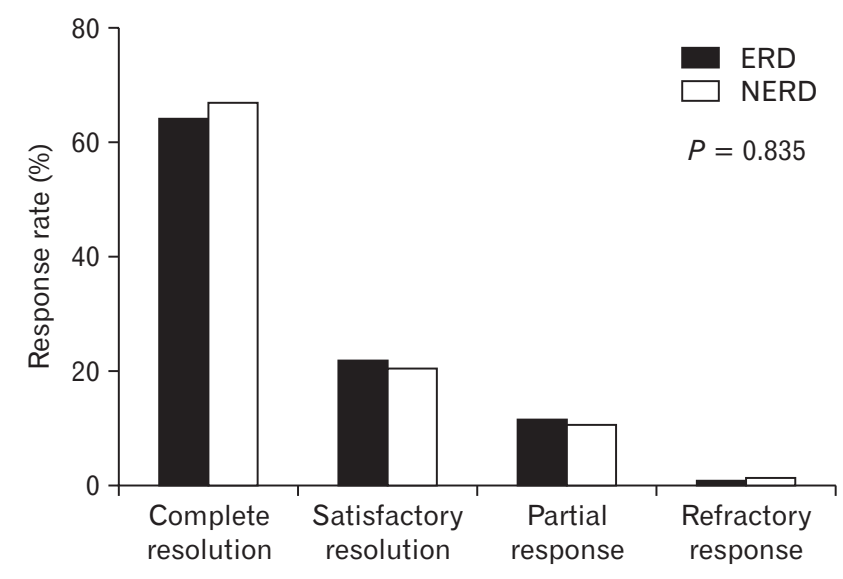

Figure 2. Response at the end of the treatment. Among the 611 subjects assessed, a complete resolution was present in $401(65.6 \%)$, a satisfactory resolution in $132(21.6 \%)$, a partial response in $70(11.5 \%)$ and a refractory response in $8(1.3 \%)$. The treatment response did not differ between patients with erosive reflux disease (ERD) and nonerosive reflux disease (NERD). able to be assessed in 343, and of these, 164 subjects (47.8\%) experienced recurrent symptoms following treatment, and the recurrence rate did not differ between patients with ERD and NERD ( $45.1 \%$ vs $51.3 \%, P=0.250)$.

Among the 329 subjects without CR at week 4, 111 achieved $\mathrm{CR}$ at week 8 and 218 did not. However, response at week 4 did not differ between the subjects with and without CR at week 8 .

\section{Factors Associated with Gastroesophageal Reflux Disease Recurrence}

Factors associated with recurrence after complete resolution of GERD were investigated. There were no significant differences between patients with and without recurrence with respect to age, gender, BMI, W/H ratio, smoking, alcohol consumption, presence of reflux esophagitis, and atypical esophageal symptoms (Table 2). However, patients with acid regurgitation, and both acid regurgitation and heartburn, were more likely to recur than those with heartburn alone $(31.1 \%$ and $43.3 \%$ vs $25.6 \%$, respectively; $P=$ 
Table 2. Factors Associated with the Recurrence of Gastroesophageal Reflux Disease

\begin{tabular}{|c|c|c|c|}
\hline Variables & $\begin{array}{l}\text { Recurrence } \\
(\mathrm{n}=164)\end{array}$ & $\begin{array}{l}\text { No recurrence } \\
\quad(\mathrm{n}=179)\end{array}$ & $P$-value \\
\hline Age (yr) & $54.3 \pm 11.7$ & $55.2 \pm 11.8$ & 0.476 \\
\hline Gender (male) & $74(45.1)$ & $83(46.4)$ & 0.817 \\
\hline Body mass index $\left(\mathrm{kg} / \mathrm{m}^{2}\right)$ & $23.6 \pm 3.0$ & $23.9 \pm 3.2$ & 0.520 \\
\hline Waist/hip ratio & $0.9 \pm 0.1$ & $0.9 \pm 0.1$ & 0.285 \\
\hline Hypertension & $32(19.5)$ & $34(19.0)$ & 0.903 \\
\hline Smoking & & & 0.999 \\
\hline Non-smoker & $117(71.3)$ & $128(71.5)$ & \\
\hline Ex-smoker & $21(12.8)$ & $23(12.9)$ & \\
\hline Current smoker & $26(15.9)$ & $28(15.6)$ & \\
\hline Days of drinking per week & $1.7 \pm 2.2$ & $1.4 \pm 1.8$ & 0.224 \\
\hline ERD:NERD & $87(53.1): 77(46.9)$ & $106(59.2): 73(40.8)$ & 0.250 \\
\hline Typical reflux symptom & & & 0.001 \\
\hline Heartburn & $42(25.6)$ & $80(44.7)$ & \\
\hline Acid regurgitation & $51(31.1)$ & $43(24.0)$ & \\
\hline Both symptoms & $71(43.3)$ & $56(31.3)$ & \\
\hline Atypical esophageal symptom & $142(86.6)$ & $150(83.8)$ & 0.469 \\
\hline Complete remission & & & 0.051 \\
\hline At week 4 & $111(44.6)$ & $138(55.4)$ & \\
\hline At week 8 & $53(56.4)$ & $41(43.6)$ & \\
\hline
\end{tabular}

ERD, erosive reflux disease; NERD, non-erosive reflux disease Data are shown as the mean $\pm \mathrm{SD}$ or number $(\%)$ of patients.

Table 3. Multivariate Analysis of Factors Associated with the Recurrence of Gastroesophageal Reflux Disease

\begin{tabular}{llc}
\hline \multirow{2}{*}{ Variables } & \multicolumn{2}{c}{ Multivariate analysis } \\
\cline { 2 - 3 } & \multicolumn{1}{c}{ OR $(95 \% \mathrm{CI})$} & $P$-value \\
\hline Typical reflux symptom & \\
Heartburn & 1.000 & 0.004 \\
Acid regurgitation & $2.249(1.293-3.912)$ & 0.001 \\
Both symptoms & $2.330(1.392-3.901)$ & \\
Complete remission & \\
At week 4 & 1.000 & 0.090 \\
At week 8 & $1.526(0.937-2.488)$ & \\
\hline
\end{tabular}

$\mathrm{OR}$, odds ratio; $\mathrm{CI}$, confidence interval.

0.001). In addition, patients who achieved $\mathrm{CR}$ at week 4 showed a tendency to recur less often than those who achieved $\mathrm{CR}$ at week 8 , with marginal statistical significance ( $44.6 \%$ vs $56.4 \%, P=0.051$ ).

Multivariate analysis using the two significant factors from univariate analysis revealed that acid regurgitation and both acid regurgitation and heartburn were independent risk factors associated with GERD recurrence (Table 3). Compared with heartburn, the ORs of acid regurgitation and both acid regurgitation and heartburn were 2.249 (95\% CI, 1.293-3.912, $P=0.004)$ and $2.330(95 \%$
CI, 1.392-3.901, $P=0.001)$, respectively.

\section{Health-related Quality of Life}

Figure 3 shows the change in HRQoL after treatment, according to the outcome. The EQ descriptive score showed a marked improvement in subjects with $\mathrm{CR}$ compared with those without $\mathrm{CR}$ (change from baseline of $0.06 \pm 0.10$ vs $0.03 \pm 0.08, P<0.001$ ) The EQ VAS score also showed greater improvement in subjects with $\mathrm{CR}$ than in those without CR (change from baseline of $14.3 \pm$ 17.9 vs $9.4 \pm 16.4, P=0.001)$.

Figure 4 shows the change in HRQoL according to the presence of recurrence after CR. Among the subjects with CR, the EQ descriptive score at the end of the treatment did not differ between subjects with and without recurrence $(0.92 \pm 0.05$ vs $0.93 \pm 0.04$, $P=0.732$ ), but worsened more during follow-up in subjects with recurrence compared with those without recurrence (change from the end of treatment at recurrence vs. at month $12,-0.02 \pm 0.08$ vs $0.00 \pm 0.06, P=0.003)$. However, the EQ VAS score at the end of the treatment was lower in subjects with recurrence than in those without recurrence $(79.6 \pm 12.9$ vs $82.5 \pm 12.8, P=0.042)$, but the change in EQ VAS during follow-up did not differ between subjects with and without recurrence (change from the end of treat- 


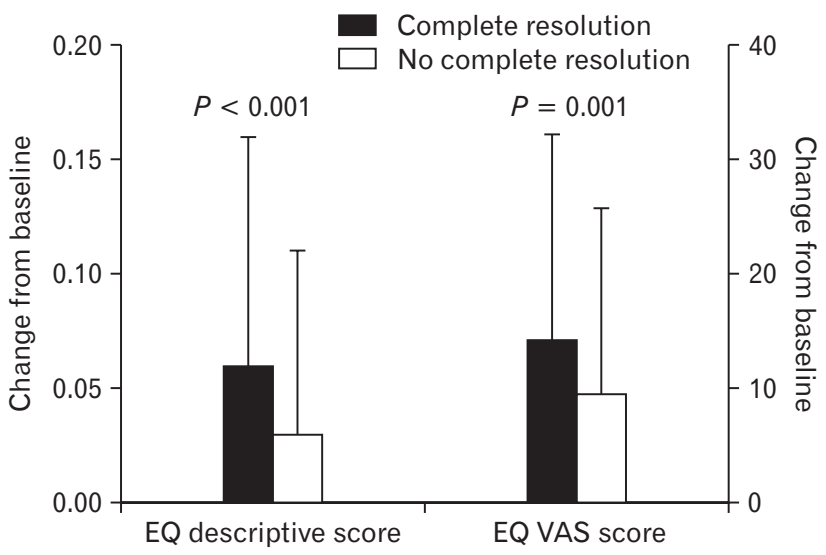

Figure 3. Change in health-related quality of life after the end of treatment according to the presence of recurrence. The EQ descriptive score and the visual analogue scale (VAS) score shows a greater improvement in subjects with complete resolution compared with those without complete resolution.

ment at recurrence vs. at month $12,-6.3 \pm 17.3$ vs $-3.4 \pm 16.3, P$ $=0.131)$.

The EQ descriptive score at baseline and its changes after treatment and recurrence did not differ between subjects with ERD and NERD $(0.87 \pm 0.10$ vs $0.86 \pm 0.10, P=0.179 ; 0.04 \pm 0.10$ vs $0.05 \pm 0.09, P=0.260$; and $-0.01 \pm 0.07$ vs $-0.01 \pm 0.08, P$ $=0.919$, respectively). However, the EQ VAS score at baseline was higher in subjects with ERD than in those with NERD (66.2 \pm 17.3 vs $62.7 \pm 18.4, P=0.005)$. Its changes after treatment and recurrence did not differ between subjects with ERD and NERD $(11.4 \pm 16.0$ vs $14.4 \pm 19.4, P=0.051$ and $-5.3 \pm 15.8$ vs -4.0 $\pm 18.1, P=0.498$, respectively).

\section{Discussion}

Considering the increasing prevalence of GERD in Asia, efforts to establish optimal treatment strategies are necessary. However, data regarding the outcomes of PPI therapy in GERD from Asian countries, including Korea, are limited. ${ }^{10-12}$ Furthermore, the impact of GERD on the QoL according to the treatment response and recurrence following the treatment has yet to be evaluated. Thus the present study sought to evaluate the treatment outcome of PPI therapy in a Korean GERD population, to further investigate its prognostic factors, and to assess its impact on QoL. In this study population, CR was achieved in $65.6 \%$ after PPI therapy, however almost half of them experienced recurred symptoms following treatment. Patients with acid regurgitation at baseline were more likely to recur than those without. HRQoL was markedly improved in

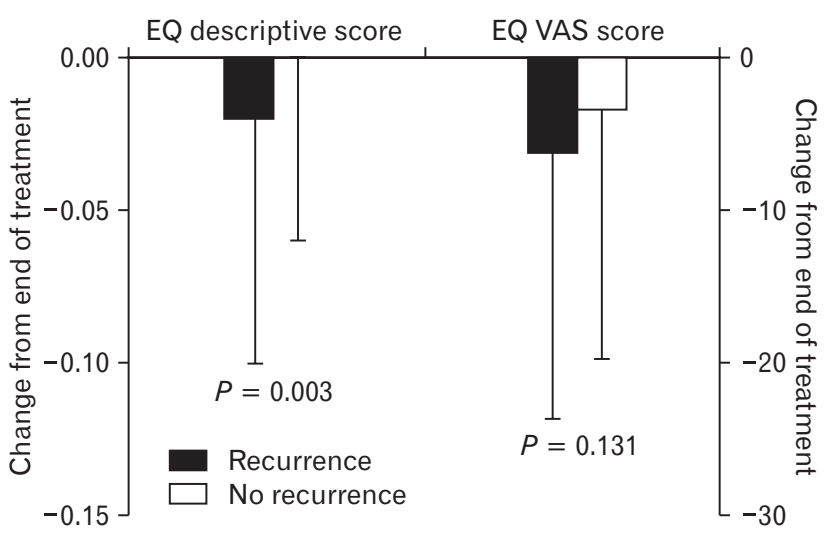

Figure 4. Change of health-related quality of life after the end of treatment according to the presence of recurrence. EQ descriptive score worsened during follow-up in subjects with recurrence compared with those without recurrence, while EQ visual analogue scale (VAS) score did not differ between subjects with and without recurrence.

patients with $\mathrm{CR}$ compared with those without, and worsened more during follow-up in patients with recurrence compared with those without.

In our results, complete relief on PPI therapy was similarly observed between the patients with ERD and NERD, however, this is in contrast to data from other studies. PPI therapy has been associated with a greater rate of relief in patients with ERD compared with those with NERD. ${ }^{20-22}$ In an Asian study, PPI response rates at 8 weeks were also different between the patients with ERD and NERD $(72.4 \%$ vs $66.6 \%, P=0.02) .{ }^{11}$ Other recent Asian studies also show lower similar findings. ${ }^{12,23,24}$ In the present study, ERD was determined according to the LA classification system. ${ }^{19}$ Despite the exclusion of minimal changes constituting a grade of reflux esophagitis in this system, uncertainty remains in the detection of mucosal breaks, leading to an inconsistency among endoscopists. ${ }^{25,26}$ Thus, there may be a small possibility that patients without a true mucosal break were erroneously included into the ERD group. In fact, subjects with ERD were more prevalent (58.6\%) than those with NERD in the present study.

After achieving $\mathrm{CR}$, almost half of the subjects experienced recurrent symptoms within 12 months. The recurrence rate did not differ between patients with ERD and NERD. Maintenance PPI therapy was administered according to the attending physicians' judgement. The proportion of subjects with maintenance, ondemand or continuous medication, was not included in the present study. However, our results are consistent with a prior Asian study. ${ }^{11}$ In that study, $44.3 \%$ of the subjects in the erosive esophagitis group and $43.2 \%$ in the NERD group had symptomatic relapses without 
a difference between the two groups. In addition, it is well known that recurrence of esophagitis symptoms is frequent. ${ }^{3,27}$ Thus, we explored the clinical factors associated with recurrence after $\mathrm{CR}$ of GERD. As a result, the presence of regurgitation at baseline was revealed as an independent prognostic factor for recurrence. $\mathrm{Pa}-$ tients complaining of regurgitation were more than twice as likely to recur than those without regurgitation. This observation is supported in part by previous findings. ${ }^{28,29}$ According to the data from the clinical trials, regurgitation is less responsive to acid suppression than heartburn in patients with GERD. Thus our results indicate that regurgitation is not only a risk factor for an incomplete treatment response but also for recurrence in patients with GERD.

The impact of recurrence of GERD on HRQoL has not been previously studied. To our knowledge, this is the first study showing that the improved HRQoL on achievement of $\mathrm{CR}$ worsens more during follow-up in patients with recurrence compared with those without. In addition, the impact of GERD on HRQoL did not differ according to the presence of esophagitis. From our results, we suggest that complete symptom relief should be achieved and that recurrence needs to be prevented, in order to improve $\mathrm{QoL}$ in patients with GERD.

The prevalence of GERD is relatively low in Eastern countries. ${ }^{4-9}$ Obesity may be the important cause of discrepancy in the prevalence of GERD between Eastern and Western countries. ${ }^{30}$ Obesity was associated with frequent GERD symptoms in a dosedependent manner. ${ }^{31}$ Besides symptoms, increased esophageal acid and non-acid exposure was observed in obese patients with GERD. ${ }^{32,33}$ These observations could explain a decreased response to PPI therapy in obese patients with GERD. ${ }^{34}$ Although no definite data exist regarding the role of diet in GERD, ${ }^{35,36}$ high-fat diet is frequent in the obese patients and appears to induce GER by itself..$^{37}$ Thus, the different lifestyle, in particular diet, may cause ethnic and geographic differences in GERD. In addition, the higher prevalence of Helicobacter pylori and atrophic gastritis in East Asian countries may be another factor in the lower prevalence of GERD. Gastric acid secretion is a pathophysiological factor for GERD ${ }^{38}$ The atrophic pan-gastritis causes a marked suppression of acid secretion in $H$. pylori infected population. ${ }^{39}$ However, data are conflicting in the association between $H$. pylori infection and GERD. The present study has some limitations. The treatment response could only be assessed in $74 \%$ of the enrolled subjects due to follow-up loss, despite regular phone calls. In addition, information regarding maintenance therapy is not included in this study. Conversely, the present study also has several strengths. The first important strength is that this study was conducted nationwide with a relatively large GERD population. Secondly, this is the first study to show that QoL worsens due to recurrence of GERD. Lastly, we reveal that regurgitation is a risk factor for recurrence in patients with GERD. In conclusion, we should achieve complete symptom relief and attempt to prevent relapse in patients with GERD, which would result in an improvement of QoL. After CR, we need to give increased attention to patients complaining of regurgitation.

Acknowlegements: We are indebted to collaborators: Hyung Seok Park, Sun Moon Kim, Sung Kook Kim, Young-Tae Bak, Bora Keum, Jin Tae Jung, Gwang Ha Kim, Dong Ho Lee, Kook Lae Lee, Hwoon-Yong Jung, Kwang Jae Lee, Seong Hwan Kim, Soo Teik Lee, Hyun Yong Jeong, and Tae Oh Kim.

Financial support: This study was sponsored by AstraZeneca Korea (PHO3112185).

\section{Conflicts of interest: None.}

Author contributions: Yang Won Min contributed to data analysis and interpretation, and drafted the manuscript; Yong Woon Shin, Gab Jin Cheon, Kyung Sik Park, Hyun Soo Kim, Chong-Il Sohn, Tae Nyeun Kim, and Hyeung Cheol Moon recruited subjects and performed critical revision of the manuscript; and PoongLyul Rhee designed and coordinated the study, contributed to data interpretation, and edited the manuscript.

\section{References}

1. Katz PO, Gerson LB, Vela MF. Guidelines for the diagnosis and management of gastroesophageal reflux disease. Am J Gastroenterol 2013;108:308-328.

2. Bader JP, Delchier JC. Clinical efficacy of pantoprazole compared with ranitidine. Aliment Pharmacol Ther 1994;8(suppl 1):47-52.

3. Schindlbeck NE, Klauser AG, Berghammer G, Londong W, MüllerLissner SA. Three year follow up of patients with gastrooesophageal reflux disease. Gut 1992;33:1016-1019.

4. Wong BC, Kinoshita Y. Systematic review on epidemiology of gastroesophageal reflux disease in Asia. Clin Gastroenterol Hepatol 2006; 4:398-407.

5. Bai Y, Du Y, Zou D, et al. Gastroesophageal reflux disease questionnaire (GerdQ) in real-world practice: a national multicenter survey on 8065 patients. J Gastroenterol Hepatol 2013;28:626-631.

6. Cho YK, Kim GH, Kim JH, et al. Diagnosis of gastroesophageal reflux disease: a systematic review. Korean J Gastroenterol 2010;55:279-295.

7. Song JH, Chung SJ, Lee JH, et al. Relationship between gastroesophageal reflux symptoms and dietary factors in Korea. J Neurogastroenterol Motil 2011;17:54-60. 
8. Jung HK. Epidemiology of gastroesophageal reflux disease in Asia: a systematic review. J Neurogastroenterol Motil 2011;17:14-27.

9. Jung HS, Choi MG, Baeg MK, et al. Obesity is associated with increasing esophageal acid exposure in korean patients with gastroesophageal reflux disease symptoms. J Neurogastroenterol Motil 2013;19:338-343.

10. Wong WM, Lai KC, Lam KF, et al. Onset and disappearance of reflux symptoms in a Chinese population: a 1-year follow-up study. Aliment Pharmacol Ther 2004;20:803-812.

11. Lee ES, Kim N, Lee SH, et al. Comparison of risk factors and clinical responses to proton pump inhibitors in patients with erosive oesophagitis and non-erosive reflux disease. Aliment Pharmacol Ther 2009;30:154164.

12. Goh KL, Choi KD, Choi MG, et al. Factors influencing treatment outcome in patients with gastroesophageal reflux disease: outcome of a prospective pragmatic trial in Asian patients. BMC Gastroenterol 2014;14: 156.

13. Kim SE, Kim N, Oh S, et al. Predictive factors of response to proton pump inhibitors in korean patients with gastroesophageal reflux disease. J Neurogastroenterol Motil 2015;21:69-77.

14. Becher A, El-Serag H. Systematic review: the association between symptomatic response to proton pump inhibitors and health-related quality of life in patients with gastro-oesophageal reflux disease. Aliment Pharmacol Ther 2011;34:618-627.

15. Gerson LB, Fass R. A systematic review of the definitions, prevalence, and response to treatment of nocturnal gastroesophageal reflux disease. Clin Gastroenterol Hepatol 2009;7:372-378.

16. Kulig M, Leodolter A, Vieth M, et al. Quality of life in relation to symptoms in patients with gastro-oesophageal reflux disease-- an analysis based on the ProGERD initiative. Aliment Pharmacol Ther 2003;18:767-776.

17. Pace F, Negrini C, Wiklund I, Rossi C, Savarino V, Italian One Investigators Study Group. Quality of life in acute and maintenance treatment of non-erosive and mild erosive gastro-oesophageal reflux disease. Aliment Pharmacol Ther 2005;22:349-356.

18. EuroQol Group. EuroQol--a new facility for the measurement of healthrelated quality of life. Health Policy 1990;16:199-208.

19. Armstrong D, Bennett JR, Blum AL, et al. The endoscopic assessment of esophagitis: a progress report on observer agreement. Gastroenterology 1996;111:85-92.

20. Fass R. Erosive esophagitis and nonerosive reflux disease (NERD): comparison of epidemiologic, physiologic, and therapeutic characteristics. J Clin Gastroenterol 2007;41:131-137.

21. Vantrappen G, Rutgeerts L, Schurmans P, Coenegrachts JL. Omeprazole $(40 \mathrm{mg})$ is superior to ranitidine in short-term treatment of ulcerative reflux esophagitis. Dig Dis Sci 1988;33:523-529.

22. Bardhan KD. The role of proton pump inhibitors in the treatment of gastro-oesophageal reflux disease. Aliment Pharmacol Ther 1995;9(suppl 1): 15-25.

23. Cho YK, Choi MG, Lim CH, et al. Diagnostic value of the PPI test for detection of GERD in Korean patients and factors associated with PPI responsiveness. Scand J Gastroenterol 2010;45:533-539.
24. Matsuhashi N, Kudo M, Yoshida N, et al. Factors affecting response to proton pump inhibitor therapy in patients with gastroesophageal reflux disease: a multicenter prospective observational study. J Gastroenterol 2015;50:1173-1183.

25. Pandolfino JE, Vakil NB, Kahrilas PJ. Comparison of inter- and intraobserver consistency for grading of esophagitis by expert and trainee endoscopists. Gastrointest Endosc 2002;56:639-643.

26. Lee YC, Lin JT, Chiu HM, et al. Intraobserver and interobserver consistency for grading esophagitis with narrow-band imaging. Gastrointest Endosc 2007;66:230-236.

27. Vigneri S, Termini R, Leandro G, et al. A comparison of five maintenance therapies for reflux esophagitis. N Engl J Med 1995;333:11061110.

28. Kahrilas PJ, Howden CW, Hughes N. Response of regurgitation to proton pump inhibitor therapy in clinical trials of gastroesophageal reflux disease. Am J Gastroenterol 2011;106:1419-1425.

29. Kahrilas PJ, Jonsson A, Denison H, Wernersson B, Hughes N, Howden CW. Regurgitation is less responsive to acid suppression than heartburn in patients with gastroesophageal reflux disease. Clin Gastroenterol Hepatol 2012;10:612-619.

30. Mion F, Dargent J. Gastro-oesophageal reflux disease and obesity: pathogenesis and response to treatment. Best Pract Res Clin Gastroenterol 2014;28:611-622.

31. Jacobson BC, Somers SC, Fuchs CS, Kelly CP, Camargo CA Jr. Bodymass index and symptoms of gastroesophageal reflux in women. $\mathrm{N}$ Engl J Med 2006;354:2340-2348.

32. Crowell MD, Bradley A, Hansel S, et al. Obesity is associated with increased 48-h esophageal acid exposure in patients with symptomatic gastroesophageal reflux. Am J Gastroenterol 2009;104:553-559.

33. Hajar N, Castell DO, Ghomrawi H, Rackett R, Hila A. Impedance $\mathrm{pH}$ confirms the relationship between GERD and BMI. Dig Dis Sci 2012; 57:1875-1879.

34. Sheu BS, Cheng HC, Chang WL, Chen WY, Kao AW. The impact of body mass index on the application of on-demand therapy for Los Angeles grades A and B reflux esophagitis. Am J Gastroenterol 2007;102: 2387-2394.

35. Kaltenbach T, Crockett S, Gerson LB. Are lifestyle measures effective in patients with gastroesophageal reflux disease? An evidence-based approach. Arch Intern Med 2006;166:965-971.

36. Festi D, Scaioli E, Baldi F, et al. Body weight, lifestyle, dietary habits and gastroesophageal reflux disease. World J Gastroenterol 2009;15:16901701.

37. Fox M, Barr C, Nolan S, Lomer M, Anggiansah A, Wong T. The effects of dietary fat and calorie density on esophageal acid exposure and reflux symptoms. Clin Gastroenterol Hepatol 2007;5:439-444.

38. Cadiot G, Bruhat A, Rigaud D, et al. Multivariate analysis of pathophysiological factors in reflux oesophagitis. Gut 1997;40:167-174.

39. McColl KE. Review article: Helicobacter pylori and gastro-oesophageal reflux disease--the European perspective. Aliment Pharmacol Ther 2004; 20(suppl 8):36-39. 